\title{
Influence of Daphnia infochemicals on functional traits of Microcystis strains (Cyanobacteria)
}

\author{
Ineke van Gremberghe • Pieter Vanormelingen • \\ Katleen Van der Gucht · Antoniya Mancheva • \\ Sofie D'hondt · Luc De Meester · Wim Vyverman
}

Received: 16 January 2009/Revised: 10 July 2009/Accepted: 13 July 2009

(C) Springer Science+Business Media B.V. 2009

\begin{abstract}
We conducted a laboratory experiment to investigate the influence of Daphnia infochemicals on growth rate, microcystin production, colony formation and cell size of eight Microcystis strains isolated from two lakes. The strains were characterized genetically by their $16 \mathrm{~S}-23 \mathrm{~S}$ rDNA ITS sequence. The experiment was composed of four treatments: (1) a control using filtered WC medium, (2) addition of Scenedesmus obliquus culture medium filtrate, (3) addition of Daphnia magna culture medium filtrate and (4) addition of sodium octyl sulphate, a commercially available Daphnia infochemical. Our results showed that sympatric strains differed strongly for the measured functional traits, while no correlations between traits were found. Between-strain differences in growth rate, microcystin production, colony formation and cell size were generally larger than the differences in phenotypes
\end{abstract}

Handling editor: D. P. Hamilton

I. van Gremberghe $(\bowtie) \cdot$ P. Vanormelingen .

K. Van der Gucht · A. Mancheva - S. D’hondt .

W. Vyverman

Laboratory of Protistology and Aquatic Ecology, Ghent University, Krijgslaan 281-S8, 9000 Ghent, Belgium

e-mail: Ineke.vanGremberghe@UGent.be

L. De Meester

Laboratory of Aquatic Ecology and Evolutionary Biology,

Katholieke Universiteit Leuven, Charles Debériotstraat

32, 3000 Leuven, Belgium observed between treatments. Despite this, several strains reacted to the infochemicals by changing functional trait values. Daphnia culture medium filtrate and, to a lesser extent, sodium octyl sulphate had a negative influence on the growth rate of half of the strains and stimulated microcystin production in one strain, but the latter effect was not Daphniaspecific as Scenedesmus culture medium filtrate had the same effect. Daphnia culture medium filtrate also induced colony formation in one strain. Our data suggest that Daphnia infochemicals generally have a weak influence on growth rate, microcystin production and colony formation of Microcystis strains as compared to the inter-strain variability, while existing inducible effects are highly strain-specific.

Keywords Colony formation - Daphnia . Functional traits - Infochemicals · Microcystins . Microcystis

\section{Introduction}

Phytoplankton has evolved various morphological, biochemical and behavioural defense mechanisms against grazing of zooplankton. It has been shown for several phytoplankton species that herbivorous zooplankton can induce these defense mechanisms by releasing infochemicals (van Donk, 2007). In particular, the influence of zooplankton infochemicals on the morphology of the closely related green algae 
Scenedesmus and Desmodesmus has been intensively studied (e.g. Hessen \& van Donk, 1993; Lürling \& van Donk, 1997; Verschoor et al., 2004). The presence of infochemicals from grazers has been shown to induce changes in cell size, colony formation and spine formation in a range of species from both genera. Other chlorococcal green algae may show a similar response (van Donk et al., 1999; Luo et al., 2006). Also, several flagellated algal species regulate their recruitment rate from the sediment depending on the presence or absence of grazers in the water column (Hansson, 1996, 2000). These adaptive changes reduce phytoplankton mortality due to herbivory, while the energetic cost of the response is lowered by the fact that the defense can be attuned depending on the presence of predators (van Donk, 2007).

Among phytoplankton, cyanobacteria are very widespread and may form nuisance blooms (Huisman et al., 2005). Microcystis is a common genus that forms toxic blooms, especially in eutrophic water bodies at high temperatures (Chorus \& Bartram, 1999; Visser et al., 2005). There is contrasting evidence in the literature on the extent to which grazing by zooplankton can control the development of cyanobacterial blooms. For instance, the effect of Daphnia, a key grazer in standing waters, on Microcystis biomass is debated, as Microcystis may strongly suppress the growth of Daphnia (Ghadouani et al., 2003), while other studies have provided evidence that Daphnia may suppress developing Microcystis blooms depending on initial conditions and history (Christoffersen et al., 1993; Sarnelle, 2007). Probably, environmental conditions are also important for the outcome of these interactions. Understanding the mechanism of defense of Microcystis against predation is important to evaluate possibilities of suppressing bloom development by grazing. Previous research has shown that Microcystis blooms are typically composed of several genotypes that can differ in functional traits such as growth rate, production of microcystins (heptapeptides which are very toxic for eukaryotes), colony formation and cell size (Carrillo et al., 2003; Janse et al., 2004; Wilson et al., 2005, 2006; Kardinaal et al., 2007). With respect to the extent to which grazers may induce phenotypic shifts in these traits, the data of different studies lead to different conclusions. Zooplankton infochemicals seem to have no
(Yang et al., 2006a; Yang \& Li, 2007) or a slightly positive impact (Jang et al., 2007, 2008) on the growth rate of Microcystis. Jang et al. (2003, 2007, 2008) reported that grazing or culture medium filtrate of Daphnia magna and Moina macrocopa increased microcystin production in several Microcystis strains. In addition, Jang et al. (2003) and Ha et al. (2004) showed that grazing or culture medium filtrate of D. magna and M. macrocopa can induce colony formation in Microcystis strains. However, other studies failed to find changes in this trait induced by D. magna (Hessen \& van Donk, 1993; Yang et al., 2006b).

Given the large differences in the effects of Daphnia infochemicals on Microcystis functional traits between studies using one or a few Microcystis strains, there is a need for studies that compare several Microcystis strains. In this study, we aimed to determine whether these differences are the result of a strain-specific response to infochemicals. Therefore, we determined (1) the differences in growth rate, microcystin production, colony formation and cell size between eight Microcystis strains, (2) whether Daphnia infochemicals have an influence on these functional traits, and (3) whether the strains react differently on these infochemicals. We expected to see clear differences between the eight Microcystis strains, all growing under the same conditions, if reactions on Daphnia infochemicals in Microcystis are strain-specific. However, if culture conditions are the main cause of the differences between different studies, all strains should show a similar reaction.

\section{Materials and methods}

Isolation and genotypic characterization of Microcystis strains

Monoclonal Microcystis cultures were obtained by sampling single colonies with a micropipette from a bloom sample from a pond in the nature reserve Leeuwenhof (Ghent, Belgium) on 07/09/04 (25) and from a pond in the nature reserve Tiens Broek (Tienen, Belgium) on 10/08/05 (20). The colonies were grown in WC medium (Guillard \& Lorenzen, 1972) at a temperature of $18^{\circ} \mathrm{C}$ and a light intensity of $30 \mu \mathrm{mol}$ photons $\mathrm{m}^{-2} \mathrm{~s}^{-1}$ (light:dark cycle $=12 \mathrm{~h}: 12 \mathrm{~h}$ ). As the taxonomy of Microcystis is still largely based on 
morphology and does not correspond to genetic features (Otsuka et al., 2001), it is preferable to use genetic markers, such as the 16S-23S rDNA ITS sequence, to distinguish different Microcystis strains from each other irrespective of morphospecies identification (Janse et al., 2004). We determined the 16S23S rDNA ITS sequence of each strain, and submitted the sequences to GenBank under accession numbers FJ830618-FJ830625. We detected four distinct ITS types in Leeuwenhof and seven ITS types in Tiens Broek. Five ITS types were identified as microcystin producing genotypes (two toxic ITS types from Leeuwenhof named T1 and T2, and three toxic ITS types form Tiens Broek of which we randomly selected two ITS types named T3 and T4) and six as nonmicrocystin producing ITS types (two non-toxic ITS types form Leeuwenhof named NT1 and NT2, and four non-toxic ITS types from Tiens Broek of which we randomly selected two ITS types named NT3 and NT4), both by detecting the presence of $m c y$ genes A (Hisbergues et al., 2003) and E (Vaitomaa et al., 2003) as well as by directly measuring microcystin concentrations in cultures by ELISA (Enzyme-Linked Immuno Sorbent Assay) with SDI-EnviroGard Microcystin ELISA plate kits (see below for more details). A rDNA ITS distance tree (Neighbor Joining with Jukes and Cantor correction) was constructed using the program BioNumerics 4.5 (Applied Maths BVBA).

\section{Experimental design}

All eight selected Microcystis strains were grown under standardized conditions in WC medium at a temperature of $23^{\circ} \mathrm{C}$ and a light intensity of $120 \mu \mathrm{mol}$ photons $\mathrm{m}^{-2} \mathrm{~s}^{-1}$ (light:dark cycle $=12 \mathrm{~h}: 12 \mathrm{~h}$ ) for several generations. Exponentially growing cells were used as inoculum for the experiment. The experimental cultures were grown during eight days (from 13-09-06 to 21-09-06) in 50 ml flasks at an initial density of 200,000 cells $\mathrm{ml}^{-1}$. Four treatments were imposed for each of the eight strains: (1) a control with addition of pure filtered WC medium, (2) addition of filtered medium from a Scenedesmus obliquus culture containing 250,000 cells ml $\mathrm{ml}^{-1}$ ("Scenedesmus" treatment), (3) addition of Daphniainfochemicals obtained by filtering medium from a culture in which $300 \mathrm{D}$. magna individuals per litre grazed for $24 \mathrm{~h}$ on approximately 50,000 cells $\mathrm{ml}^{-1}$ of S. obliquus ("Daphnia" treatment) and (4) addition of filtered WC medium containing sodium octyl sulphate (final culture concentration of $1,000 \mu \mathrm{g} \mathrm{l}^{-1}$ ), a commercially available Daphnia infochemical which can induce colony formation in Scenedesmus gutwinskii as described by Yasumoto et al. (2005) ("SOS" treatment). Sterile Nalgene filter units with $\mathrm{CN}$ membrane and pore size of $0.2 \mu \mathrm{m}$ were used for filtration. Each culture flask contained $90 \%$ standard WC medium and $10 \%$ culture medium filtrate. New culture medium filtrate was added every second day for all four treatments because since the cultures were not axenic, infochemicals could be degraded by microorganisms (Lürling \& van Donk, 1997). There were three replicate cultures for each strain $\times$ treatment combination, which resulted in 96 flasks that were gently shaken by hand daily. The position of the cultures was randomized daily. The experimental design was shown in Fig. 1.

Sample analyses

The optical density (OD) of the cultures was measured with a spectrophotometer $(\lambda=750 \mathrm{~nm})$ at the start of the experiment and after 2, 5, and 8 days. Growth curves showed that all eight strains in all treatments were growing exponential for the entire duration of the experiment and the growth rate of each strain was determined by calculating the slope of the regression line between time and $\operatorname{Ln}(\mathrm{OD})$. Samples for microcystin analysis were taken after $21 \mathrm{~h}$ and after 8 days of growth. The total microcystin concentration $\left(\mu \mathrm{g} \mathrm{ml}^{-1}\right)$ in the samples was determined by ELISA. For the extraction of microcystins, the cells were boiled for $20 \mathrm{~min}$ (van der Oost, 2007). Next, the cultures were centrifuged for $10 \mathrm{~min}$ at $14,000 \mathrm{rpm}$ and the supernatant was used for ELISA. The ELISA-test was done according to the manufacturer's instructions using SDI-EnviroGard Microcystin ELISA plate kits. To calculate microcystin concentration per unit biomass, cell densities were converted into biomass (pg C $\mu \mathrm{l}^{-1}$ ) using the formula pg C cell ${ }^{-1}=0.216 \times$ volume cell $^{0.939}$ (Menden-Deuer \& Lessard, 2000). Cell biovolumes were estimated by measuring the average cell diameter of each strain using the program CellC (Selinummi et al., 2005) (see below). Microscopical pictures of the cells and colonies were taken at the start and at the end of the experiment. After 8 days of growth, $10 \mathrm{ml}$ from each culture was fixed with 
Fig. 1 Scheme of experimental set-up for one Microcystis strain (ITS type), shown in three replicate cultures. The same set-up was conducted for all eight strains. Culture medium filtrate was added every second day and the experiment was conducted for 8 days in total

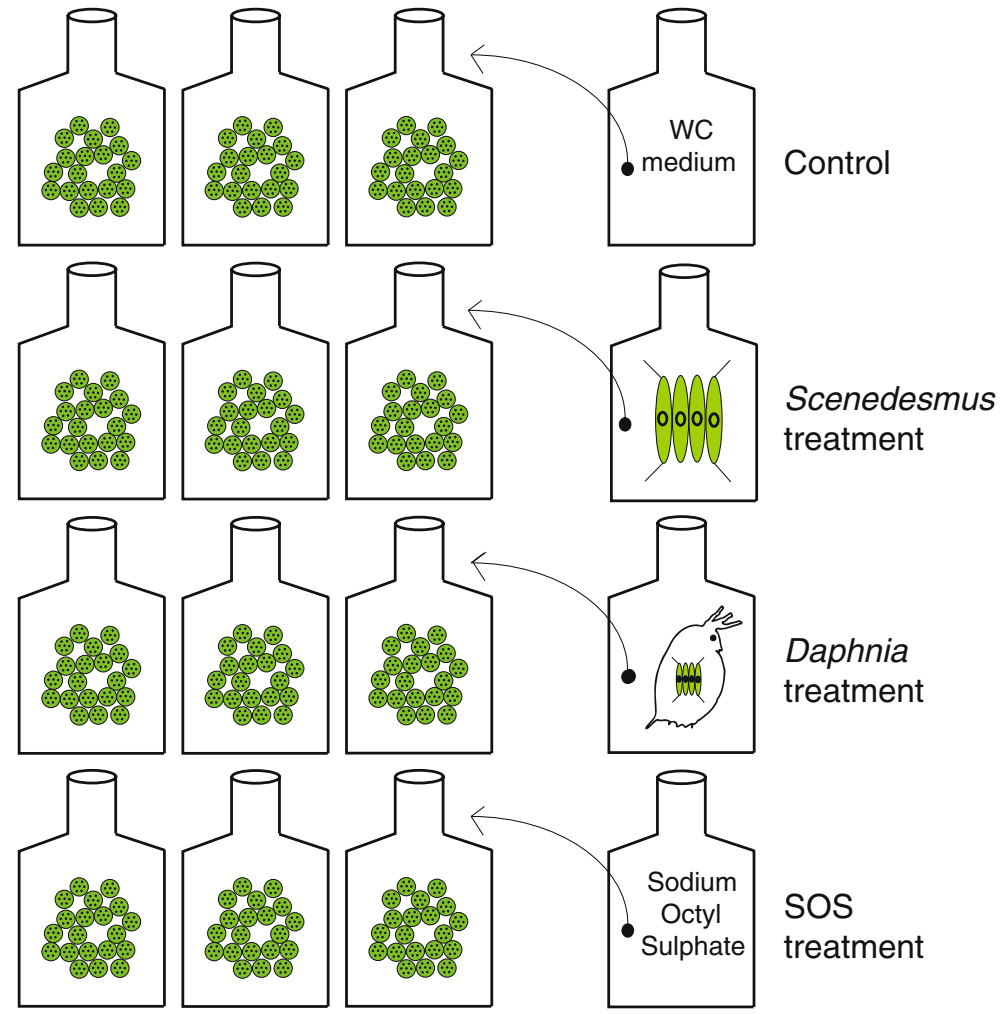

formalin (end concentration 2\%). Colony formation was determined quantitatively using the fixed samples by counting the unicellular cells with a counting chamber and recounting the cells after boiling the samples for $6 \mathrm{~min}$ to make the colonies fall apart (Joung et al., 2006). From these data, the percentage of cells in unicellular form and in colony form could be calculated. We also screened the samples for colonies and measured the size (largest diameter) of a limited number of arbitrary chosen colonies for each culture to have an idea of the size range of the colonies. In addition, $5 \mathrm{ml}$ of the fixed sample was filtered on black polycarbonate filters to measure cell size by fluorescence microscopy using the program CellC.

\section{Statistical analyses}

Correlations between the studied traits were investigated by simple and partial Mantel tests using the $\mathrm{Zt}$ software tool (Bonnet \& Van de Peer, 2002). This was done with Euclidean distance dissimilarity matrices for the four functional traits based on the mean values of the control treatment and a similarity matrix based on sequence data (\% similar nucleotides in rDNA ITS sequence) for all eight strains. To test whether there are significant differences in functional traits between strains and treatments, we carried out two-way analyses of variance (ANOVA; fixed factors: strain and treatment) followed by post hoc tests for growth rate, microcystin production and cell size, and the non-parametric Kruskal Wallis test for colony formation. Statistical analyses were performed by SPSS 15 (SPSS Inc. Chicago, USA).

\section{Results}

Figure 2 shows the rDNA ITS distance tree of the eight Microcystis strains, in which it is clear that strain T2 is more distantly related to the other strains and that there is no clustering per lake or toxicity.

Simple Mantel tests showed no significant correlations between traits, except for cell size, which was correlated with genetic distance $(r=-0.439$; $0.01<P<0.05)$ and growth rate $(r=0.417 ; 0.01<$ $P<0.05)$. However, partial Mantel tests showed that cell size and growth rate were not correlated anymore 


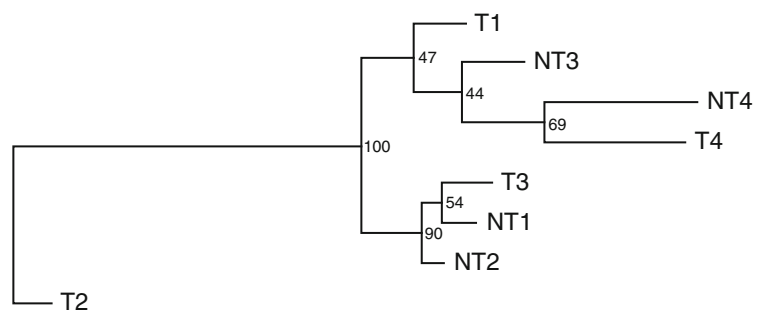

Fig. 2 Neighbor Joining tree of the eight studied Microcystis strains based on rDNA ITS (correction: Jukes and Cantor). Bootstrap values are indicated. Strains indicated with $\mathrm{T}$ are toxic strains and strains indicated with NT are non-toxic strains, strains numbered 1 and 2 are isolated from Leeuwenhof and strains numbered 3 and 4 are isolated from Tiens Broek

when controlling for genetic distances $(r=0.350$; $P>0.05)$. When correlations were recalculated without T2 (this strain differs more than average from the other strains), no significant correlations between the traits were found at all $(P>0.05)$.

Results of two-way ANOVA revealed significant differences in growth rate between strains $(F=30.94 ; \quad P<0.001)$ and between treatments $(F=11.31 ; P<0.001)$, but no strain $\times$ treatment interaction effect $(F=1.56 ; P>0.05)$. Post hoc tukey tests $(P<0.05)$ revealed four groups of strains: T4-T2-NT1, T2-NT1-NT3, NT3-T1-NT2 and NT4T3 (from slow to fast growth, no significant differences in growth rate within each group). Post hoc LSD tests showed that the Daphnia treatment had a significantly lower growth rate than the control for four of the eight strains $(0.001<P<0.01$ for T1 and NT4; $0.01<P<0.05$ for NT1 and NT2) and that the SOS treatment had a significantly lower growth rate than the control for two strains (T1 and NT4; $0.01<P<0.05$ ) (Fig. 3).

The four strains that did not produce microcystins at the start of the experiment (NT1-4) similarly did not produce microcystins in any of the treatments during the experiment. For each strain, the microcystin concentration after $21 \mathrm{~h}$ and after 8 days of growth was very similar, but the differences between the treatments were slightly larger at the end of the experiment (data not shown), so we focused on the data collected after 8 days. Two-way ANOVA revealed significant differences in microcystin production between the four toxic strains $(F=65.73$; $P<0.001)$ and between treatments $(F=3.39 ; P<$ $0.05)$, and a marginal significant strain $\times$ treatment interaction effect $(F=2.06 ; P=0.065)$ after eight days of growth. Post hoc tukey tests of the strains showed that $\mathrm{T} 2$ and $\mathrm{T} 4$ were characterized by a significantly lower microcystin concentration than $\mathrm{T} 1$ and T3 $(P<0.001)$ and that T3 produced a significantly higher microcystin concentration than $\mathrm{T} 1$ $(0.01<P<0.05)$. Post hoc LSD tests revealed that the microcystin concentration was significantly higher in the Scenedesmus, Daphnia and SOS treatments compared to the control for T3 $(0.01<$ $P<0.05$ for Scenedesmus and SOS; $0.001<P<$ 0.01 for Daphnia) (Fig. 3). It seems that microcystin production can rapidly be influenced by Daphnia infochemicals as differences between treatments were already seen in $\mathrm{T} 3$ after $21 \mathrm{~h}$ of growth (data not shown).

At the start of the experiment, all strains were composed of single cells and only a few small colonies were observed. After eight days of growth in the control treatment, only NT3 formed large colonies (size ranging from a few cells to approximately $300 \mu \mathrm{m}$ ) and four strains (T1, T2, T3 and T4) were exclusively composed of single cells. $\mathrm{T} 1$ and $\mathrm{T} 2$ also failed to produce colonies in the other treatments. Kruskal-Wallis tests for each strain separately revealed that $\mathrm{T} 4$ had a significantly higher percentage of cells in colonies in the Daphnia treatment compared to the other treatments $\left(X^{2}=10.74\right.$; $0.01<P<0.05)$ indicating that colony formation was induced by Daphnia infochemicals in this strain. For NT1, T3 and NT4, a trend for increased colony formation in the presence of Daphnia infochemicals was observed, but the pattern was not significant $(0.05<P<0.1)$ (Fig. 3).

Two-way ANOVA revealed significant differences in cell size between strains $(F=33.35 ; P<0.001)$, but not between treatments $(F=0.10 ; P>0.05)$, and no strain $\times$ treatment interaction effect $(F=0.47 ; p>0.05)$. Post hoc tukey tests showed that the strains could be divided into three significantly different groups $(P<0.05)$ according to their cell size: small (T1, NT1, NT2 and NT4), medium (T3 and NT3) and large cell size (T2 and T4) (Fig. 3).

\section{Discussion}

Overall, our results confirm the large variability in functional traits among Microcystis strains isolated 

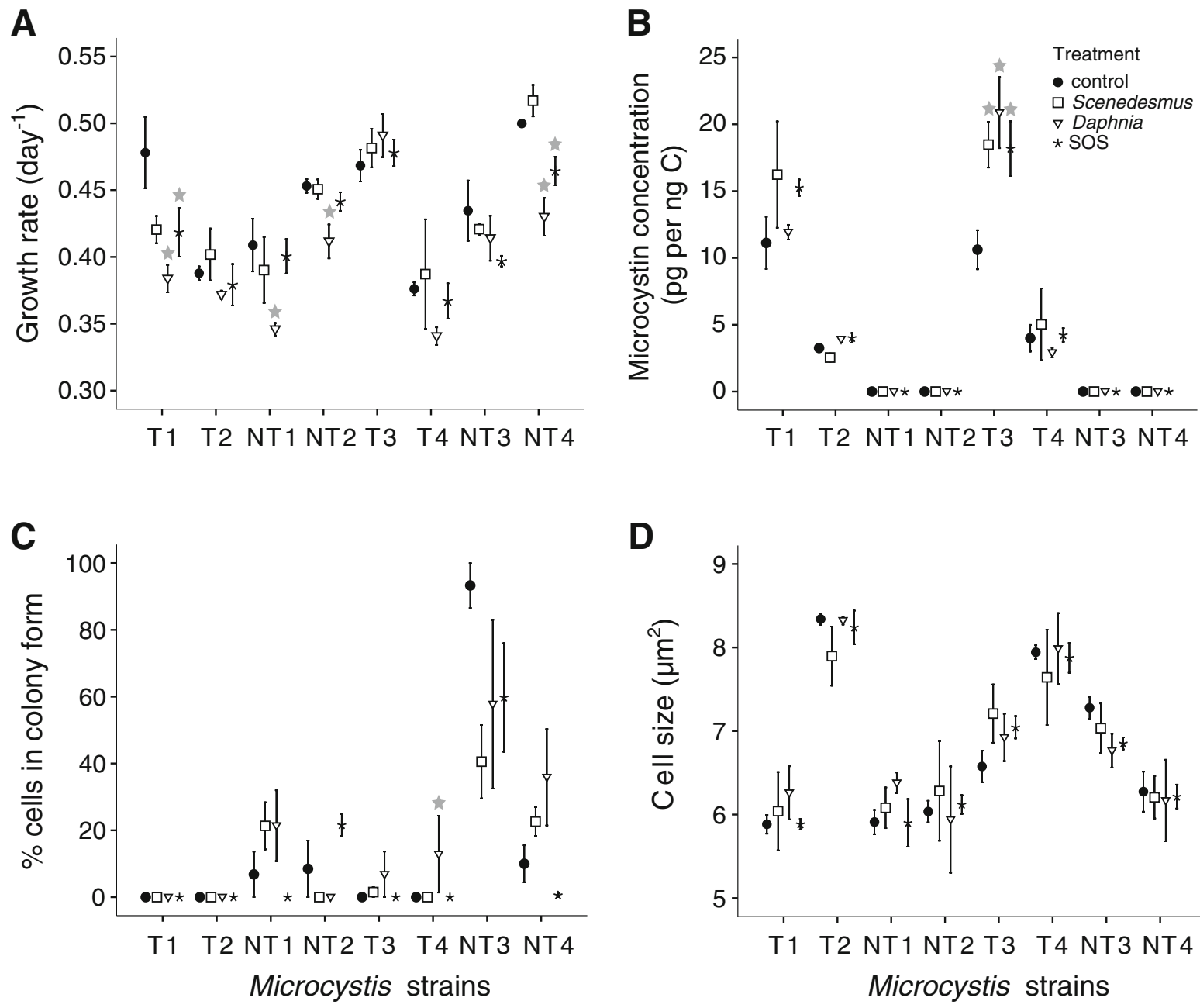

Fig. 3 Growth rate (A), microcystin concentration (B), colony formation $(\mathbf{C})$ and cell size (D) after 8 days of growth of the eight Microcystis strains in four treatments: control, Scenedesmus treatment, Daphnia treatment and sodium octyl sulphate

from the same population that has been reported before (Carrillo et al., 2003; Bañares-España et al., 2006, 2007; Wilson et al., 2006). Apart from a correlation between the genetic distances and cell size, which was due to the presence of one genetically distinct strain, no significant correlations in variation among the studied traits were found across strains. This is in accordance to Wilson et al. (2006), who did not find a correlation between growth rate and microcystin production using 32 Microcystis strains. They also found a similar growth rate for unicellular and colony forming strains. Altogether, this indicates that microcystin production and colony formation do not influence maximal growth rate.

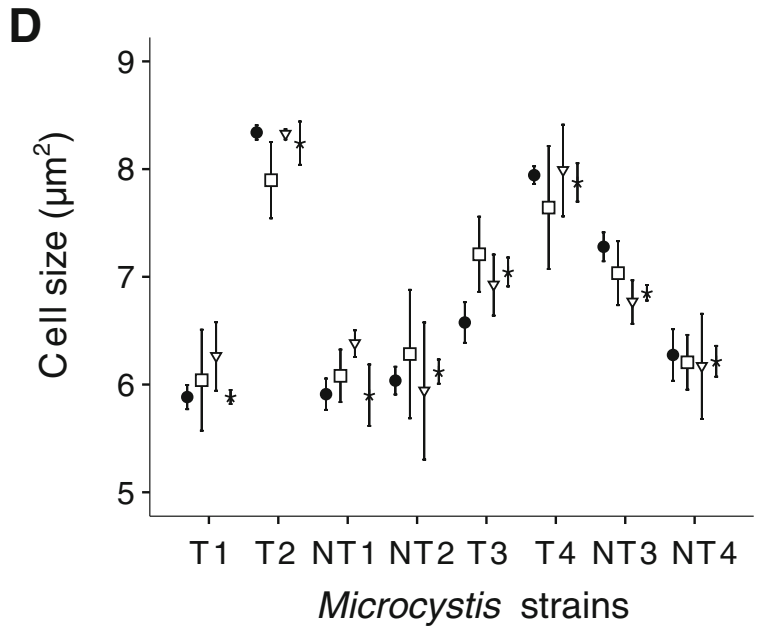

treatment (SOS). Error bars indicate the standard error of the mean. Grey asterisks indicate treatments that differ significantly $(P<0.05)$ in the studied trait from the control for the respective strain

The differences in growth rate, microcystin production, colony formation and cell size between the eight studied strains were generally larger than the differences between the treatments for each strain. Despite this, several strains reacted to the infochemicals by changing functional trait values. In contrast to previous studies (Yang et al., 2006a, Yang \& Li, 2007; Jang et al., 2007, 2008), Daphnia infochemicals had a specific negative influence on the growth rate of four of the eight studied strains, while sodium octyl sulphate had a similar but reduced effect on two of the strains. This growth cost may be due to investment of the strains in a defense against grazing other than colony formation and microcystin 
production. Possible candidates are an increase in other metabolites harmful for Daphnia (Czarnecki et al., 2006), for instance microviridin J (Rohrlack et al., 2004). This aspect should be investigated further. Daphnia culture medium filtrate induced colony formation in one strain, as reported in literature (Jang et al., 2003; Ha et al., 2004). Apparently, the infochemical involved was not sodium octyl sulphate as this substance was not effective, although the response appears to be Daphnia-specific because colony formation was not induced by Scenedesmus culture medium filtrate. In another strain, microcystin production increased in the presence of Daphnia culture medium filtrate, similar to Jang et al. (2003). However, the same effect was found for the Scenedesmus treatment indicating that the effect was not Daphnia-specific. Yet, sodium octyl sulphate also had a significant positive influence on microcystin production. Probably, more than one substance enhances microcystin production.

Our results clearly show that the response of Microcystis to zooplankton infochemicals is strongly strain-dependent, which may explain the often conflicting results reported by different studies. Interstrain variability in growth rate and colony formation as reaction to zooplankton infochemicals was also reported in Scenedesmus (Lürling, 1999; Verschoor et al., 2004). Although this was not the focus of our study, the influence of zooplankton infochemicals on traits of a particular Microcystis strain might also vary with culture conditions, as it has been shown that several environmental factors influence growth rate and microcystin production (Lukač \& Aegerter, 1993; Sivonen \& Jones, 1999; Wiedner et al., 2003). As seen in another experiment we conducted (van Gremberghe et al., 2009), the functional traits of the Microcystis strains we studied can vary under different circumstances. In addition, Lürling \& van Donk (1999) showed that temperature influenced colony induction by zooplankton infochemicals in Scenedesmus, and Hessen \& van Donk (1993) and Lürling et al. (1997) reported on a Scenedesmus strain that formed colonies upon exposure to Daphnia infochemicals in one experiment and not in another experiment conducted under the same conditions, suggesting an influence of growth phase or physiological state of the algae. Moreover, as we did not measure and adjust the nutrient concentrations in the cultures, we cannot rule out the possibility that the Scenedesmus and Daphnia treatments differed slightly from the control treatment in nutrient concentrations, which may also have influenced functional traits. However, we used a nutrient-rich medium and all the cultures were in exponential phase during the experiment, indicating that nutrients were not limited during the experiment. We can conclude that environmental conditions add another dimension to the complicated picture and merit further investigation in Microcystis. However, they do not affect the main findings of our study being (1) the large differences in functional traits between different, even sympatric, Microcystis strains, (2) a lack of correlation between functional traits, and (3) the fact that by Daphnia infochemicals induced changes in these traits are strongly strain-specific and generally smaller than differences among strains. Our data therefore also indicate that, for future research on the role of particular infochemicals on functional traits of Microcystis, it will be important to take inter-strain variability into account.

Acknowledgements We thank Jeroen Van Wichelen and Renaat Dasseville for sampling lake Leeuwenhof, Victor Chepurnov for isolating the Microcystis strains and Caroline Souffreau for helping with the sampling during the experiment. This research was financially supported by ESF EURODIVERSITY project BIOPOOL (nationally supported by BELSPO-Belgian Science Policy and FWO-Fonds Wetenschappelijk Onderzoek Vlaanderen) and Belgian project B-BLOOMS2 (nationally supported by BELSPO).

\section{References}

Bañares-España, E., V. Lopez-Rodas, C. Salgado, E. Costas \& A. Flores-Moya, 2006. Inter-strain variability in the photosynthetic use of inorganic carbon, exemplified by the $\mathrm{pH}$ compensation point, in the cyanobacterium Microcystis aeruginosa. Aquatic Botany 85: 159-162.

Bañares-España, E., V. Lopez-Rodas, E. Costas, C. Salgado \& A. Flores-Moya, 2007. Genetic variability associated with photosynthetic pigment concentration, and photochemical and nonphotochemical quenching, in strains of the cyanobacterium Microcystis aeruginosa. Fems Microbiology Ecology 60: 449-455.

Bonnet, E. \& Y. Van de Peer, 2002. Zt: a software tool for simple and partial Mantel tests. Journal of Statistical software 7: 1-12.

Carrillo, E., L. M. Ferrero, C. Alonso-Andicoberry, A. Basanta, A. Martin, V. Lopez-Rodas \& E. Costas, 2003. Interstrain variability in toxin production in populations of the cyanobacterium Microcystis aeruginosa from water-supply 
reservoirs of Andalusia and lagoons of Doñana National Park (southern Spain). Phycologia 42: 269-274.

Chorus, I. \& J. Bartram, 1999. WHO. Toxic cyanobacteria in water: a guide to their public health consequences, monitoring and management. E and FN Spon, London, UK.

Christoffersen, K., B. Riemann, A. Klysner \& M. Sondergaard, 1993. Potential role of fish predation and natural populations of zooplankton in structuring a plankton community in eutrophic lake water. Limnology and Oceanography 38: 561-573.

Czarnecki, O., M. Henning, I. Lippert \& M. Welker, 2006. Identification of peptide metabolites of Microcystis (Cyanobacteria) that inhibit trypsin-like activity in planktonic herbivorous Daphnia (Cladocera). Environmental Microbiology 8: 77-87.

Ghadouani, A., B. Pinel-Alloul \& E. E. Prepas, 2003. Effects of experimentally induced cyanobacterial blooms on crustacean zooplankton communities. Freshwater Biology 48: 363-381.

Guillard, R. R. \& C. J. Lorenzen, 1972. Yellow-green algae with chlorophyllide c. Journal of Phycology 8: 10-14.

Ha, K., M. H. Jang \& N. Takamura, 2004. Colony formation in planktonic algae induced by zooplankton culture media filtrate. Journal of Freshwater Ecology 19: 9-16.

Hansson, L. A., 1996. Behavioural response in plants: adjustment in algal recruitment induced by herbivores. Proceedings of the Royal Society of London Series BBiological Sciences 263: 1241-1244.

Hansson, L. A., 2000. Synergistic effects of food chain dynamics and induced behavioral responses in aquatic ecosystems. Ecology 81: 842-851.

Hessen, D. O. \& E. van Donk, 1993. Morphological changes in Scenedesmus induced by substances released from Daphnia. Archiv Fur Hydrobiologie 127: 129-140.

Hisbergues, M., G. Christiansen, L. Rouhiainen, K. Sivonen \& T. Borner, 2003. PCR-based identification of microcystinproducing genotypes of different cyanobacterial genera. Archives of Microbiology 180: 402-410.

Huisman, J., H. C. P. Matthijs \& P. M. Visser, 2005. Harmful Cyanobacteria. Springer, Dordrecht, The Netherlands: 243 pp.

Jang, M. H., K. Ha, G. J. Joo \& N. Takamura, 2003. Toxin production of cyanobacteria is increased by exposure to zooplankton. Freshwater Biology 48: 1540-1550.

Jang, M. H., J. M. Jung \& N. Takamura, 2007. Changes in microcystin production in cyanobacteria exposed to zooplankton at different population densities and infochemical concentrations. Limnology and Oceanography 52: 1454-1466.

Jang, M. H., K. Ha \& N. Takamura, 2008. Microcystin production by Microcystis aeruginosa exposed to different stages of herbivorous zooplankton. Toxicon 51: 882-889.

Janse, I., W. E. A. Kardinaal, M. Meima, J. Fastner, P. M. Visser \& G. Zwart, 2004. Toxic and nontoxic Microcystis colonies in natural populations can be differentiated on the basis of rRNA gene internal transcribed spacer diversity. Applied and Environmental Microbiology 70: 3979-3987.

Joung, S. H., C. J. Kim, C. Y. Ahn, K. Y. Jang, S. M. Boo \& H. M. Oh, 2006. Simple method for a cell count of the colonial cyanobacterium, Microcystis sp. Journal of Microbiology 44: 562-565.
Kardinaal, W. E. A., I. Janse, M. Kamst-Van Agterveld, M. Meima, J. Snoek, L. R. Mur, J. Huisman, G. Zwart \& P. M. Visser, 2007. Microcystis genotype succession in relation to microcystin concentrations in freshwater lakes. Aquatic Microbial Ecology 48: 1-12.

Lukač, M. \& R. Aegerter, 1993. Influence of trace-metals on growth and toxin production of Microcystis aeruginosa. Toxicon 31: 293-305.

Luo, W., S. Pflugmacher, T. Proschold, N. Walz \& L. Krienitz, 2006. Genotype versus phenotype variability in Chlorella and Micractinium (Chlorophyta, Trebouxiophyceae). Protist 157: 315-333.

Lürling, M., 1999. Grazer-induced coenobial formation in clonal cultures of Scenendesmus obliquus (Chlorococcales, Chlorophyceae). Journal of Phycology 35: 19-23.

Lürling, M. \& E. van Donk, 1997. Morphological changes in Scenedesmus induced by infochemicals released in situ from zooplankton grazers. Limnology and Oceanography 42: 783-788.

Lürling, M. \& E. van Donk, 1999. Grazer-induced colony formation in Scenedesmus acutus (Chlorophyceae): ecomorph expression at different temperatures. Journal of Phycology 35: 1120-1126.

Lürling, M., H. J. De Lange \& E. van Donk, 1997. Changes in food quality of the green alga Scenedesmus induced by Daphnia infochemicals: biochemical composition and morphology. Freshwater Biology 38: 619-628.

Menden-Deuer, S. \& E. J. Lessard, 2000. Carbon to volume relationships for dinoflagellates, diatoms, and other protist plankton. Limnology and Oceanography 45: 569-579.

Otsuka, S., S. Suda, S. Shibata, H. Oyaizu, S. Matsumoto \& M. M. Watanabe, 2001. A proposal for the unification of five species of the cyanobacterial genus Microcystis Kutzing ex Lemmermann 1907 under the rules of the Bacteriological Code. International Journal of Systematic and Evolutionary Microbiology 51: 873-879.

Rohrlack, T., K. Christoffersen, M. Kaebernick \& B. A. Neilan, 2004. Cyanobacterial protease inhibitor microviridin $\mathrm{J}$ causes a lethal molting disruption in Daphnia pulicaria. Applied and Environmental Microbiology 70: 5047-5050.

Sarnelle, O., 2007. Initial conditions mediate the interaction between Daphnia and bloom-forming cyanobacteria. Limnology and Oceanography 52: 2120-2127.

Selinummi, J., J. Seppala, O. Yli-Harja \& J. A. Puhakka, 2005. Software for quantification of labeled bacteria from digital microscope images by automated image analysis. Biotechniques 39: 859-863.

Sivonen, K. \& G. Jones, 1999. Cyanobacterial toxins. In Chorus, I. \& J. Bartram (eds), Toxic Cyanobacteria in Water-A Guide To Their Public Health Consequences Monitoring And Management. E and FN Spon, London, England: pp. 41-111.

Vaitomaa, J., A. Rantala, K. Halinen, L. Rouhiainen, P. Tallberg, L. Mokelke \& K. Sivonen, 2003. Quantitative real-time PCR for determination of microcystin synthetase E copy numbers for Microcystis and Anabaena in lakes. Applied and Environmental Microbiology 69: 7289-7297.

van der Oost, R., 2007. Cyanotoxine monitoring: standaardisering en validatie van methoden voor de Nederlandse 
Waterkwaliteitsbeheerders. Rapport STOWA onderzoek 2005 and 2006. Waternet/Waterproef, Amsterdam.

van Donk, E., 2007. Chemical information transfer in freshwater plankton. Ecological Informatics 2: 112-120.

van Donk, E., M. Lürling \& W. Lampert, 1999. Consumerinduced changes in phytoplankton: inducibility, costs, benefits, and the impact on grazers. In Tollrian, R. \& C. D. Harvell (eds), The Ecology and Evolution of Inducible Defenses. Princeton University Press, Princeton, NJ.

van Gremberghe, I., P. Vanormelingen, B. Vanelslander, K. Van der Gucht, S. D'hondt, L. De Meester \& W. Vyverman, 2009. Genotype-dependent interactions among sympatric Microcystis strains mediated by Daphnia grazing. Oikos. doi: 10.1111/j.1600-0706.2009. 17538.x.

Verschoor, A. M., I. Van Der Stap, N. R. Helmsing, M. Lürling \& E. van Donk, 2004. Inducible colony formation within the Scenedesmaceae: adaptive responses to infochemicals from two different herbivore taxa. Journal of Phycology 40: 808-814.

Visser, P. M., B. W. Ibelings, L. R. Mur \& A. E. Walsby, 2005. The ecophysiology of the harmful cyanobacterium Microcystis. Features explaining its success and measures for its control. In Huisman, J., H. C. P. Matthijs \& P. M. Visser (eds), Harmful Cyanobacteria. Springer, Dordrecht, The Netherlands: pp. 109-142.

Wiedner, C., P. M. Visser, J. Fastner, J. S. Metcalf, G. A. Codd \& L. R. Mur, 2003. Effects of light on the microcystin content of Microcystis strain PCC 7806. Applied and Environmental Microbiology 69: 1475-1481.
Wilson, A. E., O. Sarnelle, B. A. Neilan, T. P. Salmon, M. M. Gehringer \& M. E. Hay, 2005. Genetic variation of the bloom-forming cyanobacterium Microcystis aeruginosa within and among lakes: implications for harmful algal blooms. Applied and Environmental Microbiology 71: 6126-6133.

Wilson, A. E., W. A. Wilson \& M. E. Hay, 2006. Intraspecific variation in growth and morphology of the bloom-forming cyanobacterium Microcystis aeruginosa. Applied and Environmental Microbiology 72: 7386-7389.

Yang, Z. \& J. J. Li, 2007. Effects of Daphnia-associated infochemicals on the morphology and growth of Scenedesmus obliquus and Microcystis aeruginosa. Journal of Freshwater Ecology 22: 249-253.

Yang, Z., F. X. Kong, X. L. Shi \& H. S. Cao, 2006a. Differences in response to rotifer Brachionus urceus culture media filtrate between Scenedesmus obliquus and Microcystis aeruginosa. Journal of Freshwater Ecology 21: 209-214.

Yang, Z., F. X. Kong, X. L. Shi \& H. S. Cao, 2006b. Morphological response of Microcystis aeruginosa to grazing by different sorts of zooplankton. Hydrobiologia 563: $225-230$.

Yasumoto, K., A. Nishigami, M. Yasumoto, F. Kasai, Y. Okada, T. Kusumi \& T. Ooi, 2005. Aliphatic sulfates released from Daphnia induce morphological defense of phytoplankton: isolation and synthesis of kairomones. Tetrahedron Letters 46: 4765-4767. 